\title{
Food Safety Detection System Based on Internet of Things
}

\author{
Yongjun Zhang ${ }^{1,4, *}$, Changfeng Zhang ${ }^{1,2,3}$,Shenggang Wu ${ }^{1,4}$ and Guofeng Jun ${ }^{1,2,3}$ \\ ${ }^{1}$ Shandong institute of commerce and technology, China \\ ${ }^{2}$ The National Engineering Research Center for Agricultural Products Logistics, China \\ ${ }^{3}$ Shandong Province Key Laboratory of Storage and Transportation Technology of Agricultural Products, China \\ ${ }^{4}$ Shandong Province Cloud Business Big Data Engineering Research Center, China \\ ${ }^{*}$ Corresponding author
}

\begin{abstract}
With the continuous improvement of the economic level and living standards, more and more people begin to pay attention to the issues of food safety. In this paper, the design of food safety detection system is integrated by using technologies of RFID, the safety monitoring traceability, which uses the browser / server (B/S) mode that utilizes a lightweight J2EE Spring+ Spring MVC+ Hibernate framework as the core development technology. In terms of the MySQL database platform, the system can not only monitor the food safety in real time, but also significantly improve the efficiency of food safety testing.
\end{abstract}

Keywords-component; internet of things; J2EE; RFID technology; $\mathrm{B} / \mathrm{S}$

\section{INTRODUCTION}

How to ensure food safety, let consumers understand the source of food, processing procedures and purchase food, it has become an important topic of contemporary society. With the rapid development of today's information era [1], the advanced networking technology and mobile internet technology that are applied to the food safety inspection system, and realized the intelligent processing and transparent tracing in food safety detection. The use of advanced RFID technology allows consumers to query the food production information and test results quickly [2][3]. The food safety supervision and management departments can check quality information of food products through RFID code, food safety testing laboratory management system. Food safety supervision and management departments can also utilize the B/S model to achieve the instrument management, file management, personnel information management and resource management, which greatly improve the detection efficiency of food safety.

\section{Overall Design AND StRucture of THE System}

The overall design of food safety inspection system based on Internet of things that is not only to save manpower, improve the level of system automation, but also to achieve high efficiency of detection process and the transparency of detection results. The functional modules of the food safety inspection system based on the Internet of things are shown in figure 1. According to the function division, the system is divided into three parts: the instrument automatic data acquisition system, the laboratory management system and the traceability management system. Production enterprises send food to the food safety supervision agency for testing, and the automatic data acquisition system of the instrument automatically uploads the relevant data to the monitoring platform for inspecting and analyzing. The laboratory management system is mainly responsible for the workflow of quality department for management, task allocation and final report archiving, to avoid the use of paper documents, while improving the work efficiency of the staff. Traceability management system uses RFID and sensor technology to make the test results more transparent, and to design the open public monitoring platform, so that the test data can also be seen by the public at the Web clients.

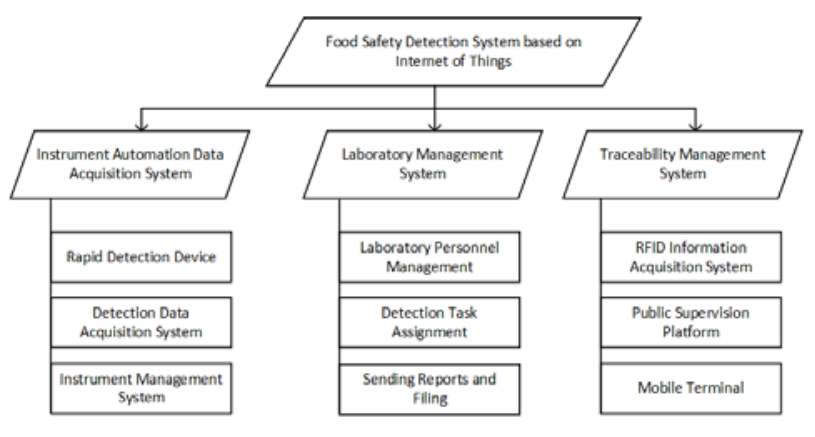

FIGURE I. FUNCTIONAL MODULES OF FOOD SAFETY DETECTION SYSTEM BASED ON INTERNET OF THINGS

\section{SySTEM SPECIFIC DESIGN AND TECHNOLOGY}

\section{A. ARM Embedded Food Safety Rapid Detection Device}

The instrument automatic data acquisition system includes traditional detection instrument and new rapid detection device. This food safety detector can probably detect content of some indexes in food, and by comparison with the standard value, that is better than the standard. For example, the detection instruments can test the concerned food and make report when the pesticide residues in vegetables, sulfur dioxide content in kelp exceed the standard. The Bluetooth communication module is set up in the fast food inspection device, and the detection data can be uploaded to the public monitoring platform in real time. 


\section{B. Instrument Data Automatic Acquisition System}

Most of the detection tasks were quantitatively detected by the food safety supervision and management departments through sophisticated instruments and equipment. Automatic collection of laboratory instrument data is the key content of laboratory automation. The instrument is connected to the laboratory management system, and the analysis instrument automatically transmits the analysis results to the management system, which improves the efficiency and correctness of data transmission. Automatic data acquisition instrument interface is divided into two categories, respectively for the instrument interface that is shown in Figure 2 with a computer as the data workstation, and in Figure 3 that is the mode of no data workstation but with instrument interface RS 232 serial for data output.

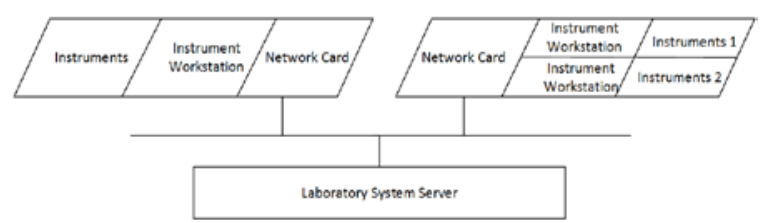

FIGURE II.

INSTRUMENT INTERFACE WITH COMPUTER AS THE DATA WORKSTATION

A data processing workstation equipment after test results can be configured to automatically export the file to the specified directory, can be directly displayed on the workstation, and the subsequent detection results of the data to be filled in in related data format, convenient batch operation, and is sent to the network without any error. The management system reads the contents of the file, reads the required data according to the established rules and writes the test result to the concerned functional database for archiving and persistence [4] [5].

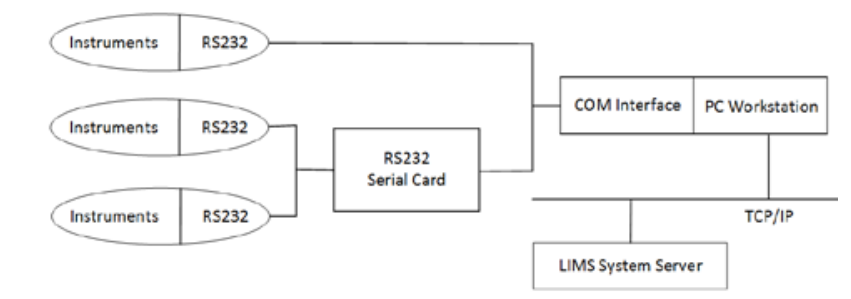

FIGURE III.

THE STRUCTURE OF INSTRUMENT WITH RS232 SERIAL PORT

The instruments with no data workstation have one thing in common, which is no corresponding instrument operating software in there. Usually, these instruments communicate with the outside through RS 232. In order to manage the instrument in a unified way, the instrument interface can be converted into Ethernet interface through the converter and connected with the management system through the Ethernet protocol.

\section{Laboratory Management System}

\section{- $\quad$ Architecture of laboratory management system}

The laboratory management system strictly controls the five major factors that will affect the laboratory results of inspections, which are the personnel, machines, raw materials, methods and environment. The laboratory management system uses Browser/Server model that is developed by J2EE platform. It is divided into three layers (UI), business layer (BLL) and data layer (DAL) according to logic of the business and is designed by using Spring MVC architecture. The relationship between the three layers is illustrated in figure 4 .

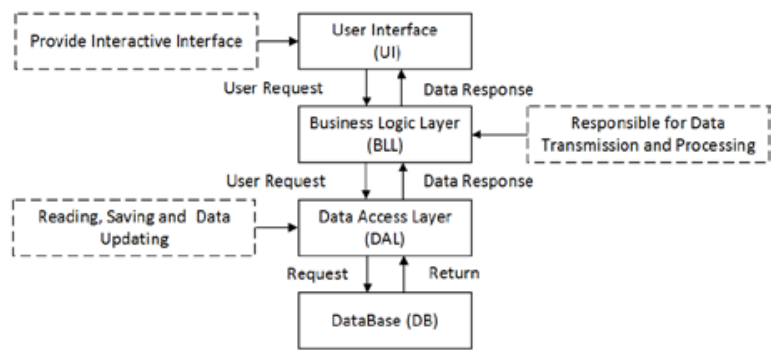

FIGURE IV. FRAMEWORK OF LABORATORY MANAGEMENT SYSTEM.

(1) Presentation layer: The presentation layer is the unification of the client layer and the Web layer. With popular speaking, the presentation layer is to provide users with an interface to achieve the well human-computer interaction. Additionally, the presentation layer is generated by Html5 + JSP/Servlet dynamic pages. The customers can operate in the browser with Ajax, which will request information after the package sent to the business layer of JavaBean processing, and the response data back to the presentation layer.

(2) Business layer: The business logic layer is the bridge between the presentation layer and the data access layer, which is mainly responsible for the data transmission and processing. The business layer receives the Ajax request sent by the browser by Controller, and uses JavaBean to process the data logically. The processing results will be stored in the data layer.

(3) Data layer: The data layer accesses the database directly, mainly realizes the data reading, saving, deleting, updating and other operations. This layer uses the Mybatis lightweight framework written by the object-oriented language of mapping language XML to manipulate and manage the data layer.

(4) Database: The data layer operates the data and sends the request to the database. The database is used to store the data and respond to the request of the data layer. After the data is processed, and it is returned to the data layer.

\section{- Design of laboratory management system}

According to the function module, laboratory management system can be divided into personnel management, detection standard management, detection management, detection task management, laboratory instrument management and test results filing management module. The system can assign administrators or testers permissions to different users. Testing personnel can also assign different permissions, such as office clerk distribution can give detection task and review the situation. The superior should make the experiment plan and assign the test task to the lower level, the lower level can choose to accept or return according to the actual situation. Each test item flow has been pre-written in the system. If the subordinate accepts the test task, the original record is filled and submitted. The original records submitted by the superior audit can be passed or returned. If passed, the final report will 
be prepared and submitted according to the test results. Final report submitted by superior audit, if passed, then filed.

\section{Internet of Things Technology}

Internet of things technology that includes the sensor, RFID technology, GPS positioning system, laser scanning and other information sensing device in accordance with the contract agreement, to anything connected with the Internet to exchange information and communication, to achieve a network intelligent identification, positioning, tracking, monitoring and management[6][7][8]. The system mainly uses RFID radio frequency identification technology, RFID technology is a wireless communication technology, and it automatically identifies the target object through radio signals, and can automatically obtain the relevant data of the target object.

\section{E. Traceability Management System Design}

The function module of traceability management system is shown in figure 5. RFID tags can store all tracing processing of food from the form of raw materials to the processing, and then to finish the transportation of food products and acquisition of results after detection, and finally achieve strict control of the whole process of the traceability. Through RFID reader can read the food related internal data. The system can also update the data in the RFID tag in real time. Because RFID tags send and receive signals through radio, the data security is relatively high. After reading all the data from the food production to the circulation market, we upload all the data to the Web end of the public monitoring platform. The public supervision platform of core technology and laboratory management system, the platform is an open system, consumers can query the safety traceability information corresponding to related food products, and it can also been downloaded the test report by calling the laboratory management system interface. In order to facilitate the consumers to query information on food safety, the system is also designed a mobile terminal App, consumers buy food in the supermarket, just use a mobile phone to scan twodimensional code on the food packaging bag, which can be traced back to food safety information, so that consumers can buy. The quality complaints or consultation may be carried out when food safety problems are found or questioned.

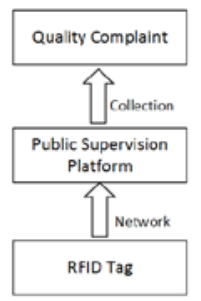

FIGURE V. FUNCTION MODULE OF TRACEABILITY MANAGEMENT SYSTEM.

\section{SUMMARY}

The system designed in this paper uses the Internet of things technology, network technology and computer technology to design a more rigorous and reliable food safety detection system from food production to food testing, and then to consumer purchase. The system ensures food safety from the root to a great extent, and solves the big problem of food safety in china. At the same time, it solves the problems of large amount of data, complex logic of task, low detection efficiency and high error rate of testing results in traditional testing laboratories. But the current system is facing the problem of food production, processing enterprises to support, and only companies willing to cooperate with us, we can make good use of data, so that food safety testing information is seen by consumers. But it is believed that food safety testing system must be the future direction of food safety development, in the era of big data, as long as the direction of this effort, the future of food safety will be more and more reassuring consumers.

\section{ACKNOWLEDGMENT}

This research was funded by the project "Key technologies of the marine granary and marine cold chain junction project along the road (2016GGH4526)”.

\section{REFERENCES}

[1] D Sun,G Wang,S Qian,Review on testing technologies and standards for food safety[J],China Measurement \& Test ,2015.

[2] Ding,X Wang,Food Safety Testing Technology Based on the Spectrophotometer and ARM[C], International Workshop on Education Technology \& Computer Science,2011,1(1):403-405.

[3] ASTM Committee.ASTM E 1578-2006 Standard Guide for Laboratory Information Management Systems (LIMS) [S]. United States: ASTM Committee, 2006.

[4] H Huang, L Liu, MO Ngadi, Recent Developments in Hyperspectral Imaging for Assessment of Food Quality and Safety [J],Sensors,2014,14 (4) :7248-7276.

[5] TM Moghaddam, SMA Razavi, M Taghizadeh,Applications of hyperspectral imaging in grains and nuts quality and safety assessment: a review[J],Journal of Food Measurement \& Characterization,2013,7 (3) : 129-140.

[6] Gamal Elmasry,Mohammed Kamruzzaman,DaWen Sun,Principles and Applications of Hyperspectral Imaging in Quality Evaluation of AgroFood Products: A Review[J],Critical Reviews in Food Science \& Nutrition, 2012 , 52 (11) :999.

[7] Application prospects of organic RFID tags for animal food tracing, Transactions of the Chinese Society of Agricultural Engineering, 2012, 28 (8) :154-158.

[8] FN Zhu, QY Zhang, Research of Fresh Meat Quality Tracing Technology and Traceability System Based on RFID [J],Applied Mechanics \& Materials, 2014 , 543-547 :4460-4463. 